\title{
Mordida cruzada unilateral funcional não provoca deslocamento de disco da ATM
}

\author{
José Antônio Bósio*
}

Para aqueles que acreditam ou tentam buscar subsídios na literatura mostrando o relacionamento de alguns fatores oclusais, como mordida cruzada unilateral funcional em crianças com disfunção de ATM, este artigo traz importantes esclarecimentos.

Pellizoni et al. ${ }^{1}$ examinaram trinta e uma crianças com idade entre 6 e 12,9 anos e as distribuíram em dois grupos. O primeiro grupo - de estudo - incluiu 15 crianças (6 meninos e 9 meninas) com mordida cruzada unilateral, envolvendo pelo menos 3 dentes, e com desvio funcional da mandíbula da relação cêntrica para a máxima intercuspidação. O segundo grupo - de controle - foi composto por 16 crianças que apresentavam oclusão normal. Os dois grupos foram submetidos a exame de ressonância magnética (RM) das articulações temporomandibulares direita e esquerda. Os filmes da RM foram obtidos na posição coronal com a boca fechada e na posição sagital com a boca aberta e fechada.

Não foi identificada nenhuma diferença intragrupo e intergrupos em relação ao gênero. Apenas uma criança do grupo de estudo apresentou deslocamento de disco intra-articular (sem redução e no mesmo lado da mordida cruzada).

Os autores ${ }^{1}$ concluíram que distúrbios da articulação temporomandibular e mordida cruzada unilateral funcional são ocorrências independentes, não tendo relação direta de causa e efeito.

O resultado deste estudo ${ }^{1}$ não nos surpreende, pelo simples fato de termos examinado várias crianças com mordida cruzada unilateral funcional, ou mesmo bilateral, ao longo dos anos, e não termos encontrado nenhum sinal ou sintoma de problema da ATM na maioria delas. Apesar de sabermos que a presença de distúrbios intracapsulares em crianças normais que nunca tiveram nenhum sinal ou sintoma da ATM gira em torno de $33 \%^{2}$, isso não implica em dizer que estas crianças precisem de tratamento para seus problemas da ATM. Os autores deste $\operatorname{artigo}^{1}$ su- $^{-}$ geriram que, talvez, alguns destes deslocamentos de discos fossem muito pequenos para serem detectados pela RM, ou um crescimento condilar assimétrico compensatório com remodelação da fossa articular fosse responsável por manter o disco na posição correta.

Não podemos esquecer que esse estudo ${ }^{1}$ não sugere que uma mordida cruzada unilateral com desvio funcional da mandíbula não deva ser tratada. Sabendo do potencial de crescimento assimétrico futuro e da facilidade com que conseguimos tratar mordidas cruzadas nessa fase, justifica-se a indicação de tratamento dessa condição numa idade precoce.

1. PELIZZONI, S. E. P. et al. Temporomandibular joint disc position and configuration in children with functional unilateral posterior crossbite: a magnetic resonance imaging evaluation. Am. J. Orthod. Dentofacial Orthop., St. Louis, v. 129, no. 6, p. 785-793, June 2006.

2. RIBEIRO, R. F.; TALLENTS, R. H.; KATZBERG, R. W.; MURPHY, W. C.; MOSS, M. E.; MAGALHAES, A. C.; TAVANO, O. The prevalence of disc displacement in symptomatic and asymptomatic volunteers aged 6 to 25 years. J. Orofac. Pain., Carol Stream, v. 11, no. 1, p. 37-47, Winter 1997.

* Ortodontista - Ohio State University (Columbus, Ohio, USA). Especialista em Dor Orofacial e Disfunção da ATM - Eastman Dental Center (Rochester, NY, USA). 